\title{
Labor Market in Multi-agent Environment Modeling Virtual Economy
}

\author{
Petr BLECHA \\ University of Hradec Králové, Hradec Králové, Czech Republic \\ petr.blecha@uhk.cz
}

\begin{abstract}
The paper is focused on the detailed overview of the part of the virtual economy project (VEP) which is developed within the research program at the University of Hradec Kralove. The introduction is mainly about the principles of the multi-agent system and how the economic methods could be developed by this approach and related works. The VEP project is described to better understanding the author's motivation and continuity for the previous research. The practical part is focused to explain how exactly these principles are used in the VEP project (what methods and technologies were used, or what influences were not been taken into account). The paper provides the graphical samples of the labor market behavior displayed as sequences of the steps by state diagrams. For the verification of the right behavior of the labor market implementation, some tests were performed and the results were analyzed. The summarization of the measured results with the relation for the future research is described at the end of the paper.
\end{abstract}

Keywords: Agent, Virtual Economy, Labor Market, Agent-based Economic Model.

\section{Introduction}

The agent-based computational economies represent a bottom-up approach for developing economic systems, where is desired behavior achieved through the interaction of its individual components - agents [6]. In this paper, the main attention is focused on an overview of the labor market in an agent-based economic sandbox environment, currently under development at the Faculty of Informatics and Management of the University of Hradec Kralove.

\subsection{Economy in Multi-Agent systems}

The economic influence is the important part of the most of the models (agent-based, mathematics, evolutionary, experts...) [5] which is trying to simulate the behavior of the real world.

The popular area of the modeling economy in the virtual environment is Agentbased computational economics (ACE). Much of existing literature indicates that ACE is a powerful tool for the ex-ante analysis of market power, and consequently for 
policymakers when evaluating structural changes and market policies. The area describes the individual economic subjects (i.e. labor market, consumer, provider...) as separate agents which can interact with each other according to its goals [4].

Gehrke in [3] explains the logistics as an important economic integral part of internal business processes which is crucial for efficient supply chain management and smooth business operation.

The Virtual Economy Project (VEP) is based on the principles of Agent-based computational economics.

\section{Virtual Economy Project}

The model described in this paper is a part of agent-based computational economics project "Virtual Economy Project" (VEP) which is primarily focused on the effective distribution of all types of products throughout the model [1].

The economic model does not aspire to be an all-inclusive real-world simulation. Some areas important for real-world economies have been deliberatively omitted, like currency markets, stock market trading, many financial services, etc., in order to keep model viable and comprehensible. Although some level of abstraction was necessary, there has been on the other hand shown a considerable effort to utilize real statistical data (from sources like Czech Statistical Office, see www.czso.cz webpage) as much as it has been relevant and useful for the functions of the model. Also, although simplified for the same reasons as mentioned above, official classifications were used to classify model components/activities plausibly (e.g. CZ-NACE classification of economic activities or RAMON - Eurostat`s Classification Servers). This helped to clarify the model while maintaining a reasonable level of detail at the same time [8].

The model is developed on Anylogic developer tool which runs on the JAVA platform. There are several agents which represent economic entities:

Table 1. Agent's overview of the Virtual Economy Project.

\begin{tabular}{llc}
\hline Agent & Description of behavior & Number of agents in model \\
\hline Mine (MA) & $\begin{array}{l}\text { Mining materials, distribute materials } \\
\text { Factory (FA) }\end{array}$ & $\begin{array}{l}\text { Ordering inputs, producing and distribute } \\
\text { products to FA, SA }\end{array}$ \\
Store (SA) & Ordering products, selling products to CA & $500-5000$ \\
Consumer (CA) & Consume products, represent workforce & $1000-500000$ \\
Transport (TA) & Transport CA or products & $50-10000$ \\
Company (CoA) & $\begin{array}{l}\text { Own MA, FA, SA or TA. Planning company } \\
\text { expansion }\end{array}$ & $1-100$ \\
Broker (BA) & Manage markets - products, services, and labor & 1 per city \\
City (CiA) & Area unit. Represent city and its services. & $1-100$ \\
\hline
\end{tabular}

In the model, the indirect communication is used. This approach is used in trading with products or workforce. In principle, the agent needs to distribute the product 
which was produced on the wholesale market. The order must be created in the standard form: name of product, amount, price and seller. This order is sent to facilitation agent Broker which decide what will be done next (add order on the wholesale or retail market) [7]. The principle of the communication is described in the picture below.

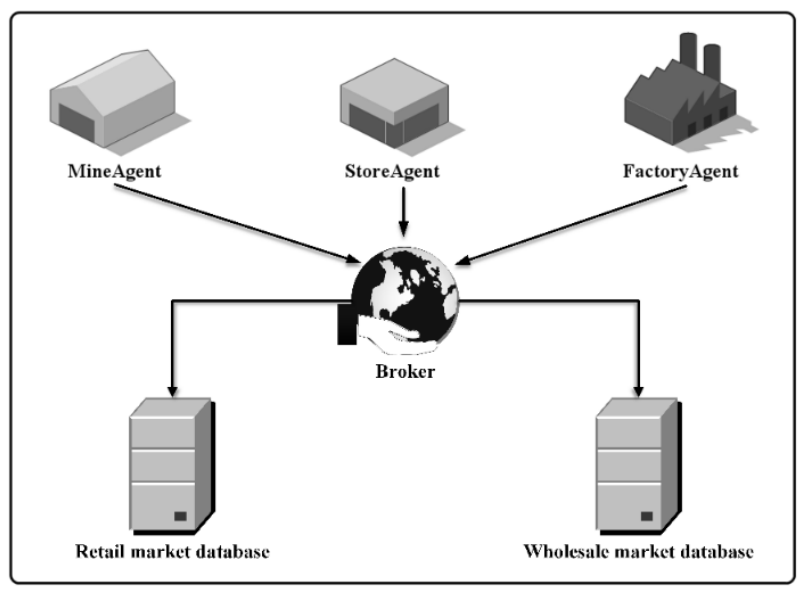

Fig. 1. The principle of indirect communication in the Virtual Economy Project.

The labor market will be implemented by the same principle as product markets. Before the implementation, the several questions need to be analyzed to choose the most appropriate option.

\section{Implementation ways of the labor market}

To implement the ways how the companies would hire the employees the main attributes of the consumer agents had to be defined:

Table 2. Consumer agent's attributes relating to the labor market.

\begin{tabular}{ll}
\hline Attribute & Description \\
\hline Age & Only CA in productive age $(15-65)$ should be employed \\
Specialization & CA prefers the workplace with its specialization. \\
City & CA prefers the workplace which is near to its permanent residence \\
\hline
\end{tabular}

The next important attribute for labor market area could be e.g. efficiency which could be calculated from attributes like experiences, education and if the CA works in its specialization field. This attribute is scheduled to be added to the future version of the VEP project. 
Table 3. Workplace attributes relating to the labor market.

\begin{tabular}{ll}
\hline Attribute & Description \\
\hline Salary & Salary for the specific workplace \\
Specialization & CA with the relevant specialization to the workplace will have a better chance \\
to be employed than CA with other specialization. & \\
City & CA prefers the workplace which is near to its permanent residence. \\
\hline
\end{tabular}

The companies prefer the employees in the relevant specialization - simple behavior of the hiring. Consumers prefer the workplace in its specialization field, near to its permanent residence and on the amount of the salary.

\subsection{Datasets of the VEP relates with Labor market}

The important part of the project is the verification of the appropriate datasets. The main statistics in the model are provided by the Czech Statistical Office [2].

The age of the consumers is calculated by the average values of the age limits:

Table 4. Age limits in the VEP project

\begin{tabular}{lcc}
\hline Age limit & Age group name & \% Consumers $(\mathbf{C Z})$ \\
\hline $1-14$ & Child & 15 \\
$15-65$ & Adult & 65 \\
$66+$ & Retired & 20 \\
\hline
\end{tabular}

The dispersion of the consumers by age is done at the start of the model by the simple function, where for each of the consumer agent the age is randomly calculated by the percent probability from the Table 4 :

At first, the value from the random generator is used to determine to which age group the CA belongs $(1-15=$ Child, $16-80=$ Adult, $81-100=$ Retired $)$. Then the age is set at the appropriate interval.

The next datasets based on the real data in VEP are e.g. gender distribution, the population of the specific cities or location of the cities on GIS map.

\section{$4 \quad$ Experiments}

For the verification of the right behavior of the age distribution and the relating hiring procedure, the simple experiments were performed.

\subsection{Age distribution experiment}

The purpose of this experiment was to ensure that the all of the age groups have the similar distribution as in the real. The experiment was performed on the total population of the 4 cities (which parameters were based on the real data) from the 
Hradec Kralove region. These cities (Hradec Kralove, Trebechovice pod Orebem, Chlumec nad Cidlinou and Jaromer) have totally 116502 people (consumers). The results of the distribution from the 10 runs of the model are following:

Table 5. Age distribution in the VEP

\begin{tabular}{ccccccc}
\hline Run & Childs & Childs ratio & \multicolumn{1}{c}{ Adults } & Adults ratio & Retired & Retired ratio \\
\hline 1 & 17501 & 0,15 & 75675 & 0,65 & 23326 & 0,20 \\
2 & 17447 & 0,15 & 76181 & 0,65 & 22874 & 0,20 \\
3 & 17416 & 0,15 & 75866 & 0,65 & 23220 & 0,20 \\
4 & 17493 & 0,15 & 75746 & 0,65 & 23263 & 0,20 \\
5 & 17535 & 0,15 & 75561 & 0,65 & 23406 & 0,20 \\
6 & 17504 & 0,15 & 75881 & 0,65 & 23117 & 0,20 \\
7 & 17316 & 0,15 & 75746 & 0,65 & 23440 & 0,20 \\
8 & 17321 & 0,15 & 75790 & 0,65 & 23391 & 0,20 \\
9 & 17525 & 0,15 & 75775 & 0,65 & 23202 & 0,20 \\
10 & 17469 & 0,15 & 75729 & 0,65 & 23304 & 0,20 \\
\hline
\end{tabular}

From these results, it is clear that the age distribution function works properly in the VEP model. It was important to verify to get the right count of the consumers which could be used as the employees within the labor market area.

\subsection{Hiring management experiment}

This simple experiment verifies that the preferences of the companies (described in chapter three) are applied properly. The consumer's decision making will be more complex and will be used in the future research. For the test this companies and consumers were available:

Table 6. Companies in the VEP model within the hiring experiment

\begin{tabular}{ccc}
\hline Company & Specialization & City \\
\hline Butchery_1 & 1 & Hradec \\
Kralove \\
Butchery_2 & 1 & Jaromer \\
Accounting_1 & 2 & Hradec \\
Accounting_2 & 2 & Kralove \\
\hline
\end{tabular}

The companies are looking for the employees with the same specialization and the location of the consumer and company is not important for them. Within this strategy the results after applying hiring process in the model run were different. 
Table 7. Consumers in the VEP model within the hiring experiment

\begin{tabular}{ccl}
\hline Consumer & Specialization & \multicolumn{1}{c}{ City } \\
\hline Consumer_1 & 1 & Hradec Kralove \\
Consumer_2 & 1 & $\begin{array}{l}\text { Jaromer } \\
\text { Chlumec nad } \\
\text { Cidlinou }\end{array}$ \\
\hline
\end{tabular}

Once the Consumer_1 was hired by Butchery_1, in the next run by Butchery_2 etc. In the main attribute, the results were always the same - specialization of the consumer was equal to the specialization of the company. It was not possible to hire e.g. Consumer_1 with specialization 1 by company Accounting_1 with specialization 2.

\section{Conclusion}

Presented simulations showed potential for testing more complex labor market behavior patterns in such virtual environments. The experiments were focused to verify if the standard and expected behavior work properly to start to implement complex algorithms. Future proceeding in the simulation will be focused on whole labor market process and its impact on the other areas (producing, transporting, trading...). Together with the involvement of more market participants, this is intended for the future work.

Acknowledgements. Support of the Specific Research Project of FIM UHK "Autonomous-socio economic systems" is gratefully acknowledged.

\section{References}

1. Blecha, P.: Supply Chains in Project of Virtual Economics on Anylogic platform. In: Sandu, A., Frunza, A., Ciulei, T., Gorghiu, G., Petrovici, A. (eds.) RETHINKING SOCIAL ACTION. CORE VALUES, pp. 161-165. MEDIMO, Iasi (2015).

2. Czech Statistical Office, www.czso.cz, last accessed 2017/10/23.

3. Gehrke, J., Herzog, O., Langer, H., Malaka, R., Porzel, R., Warden, T.: An Agent-based Approach to Autonomous Logistic Processes. KI - Künstliche Intelligenz 24(2), 137-141 (2010), http://dx.doi.org/10.1007/s13218-010-0027-1

4. Hung, M., Huang, T.: Dynamic demand for residential electricity in Taiwan under seasonality and increasing-block pricing. Energy Economics 48, 168-177 (2015). http://dx.doi.org/10.1016/j.eneco.2015.01.010

5. Marimon, R., McGrattan, E., Sargent, T.: Money as a medium of exchange in an economy with artificially intelligent agents. Journal Of Economic Dynamics And Control 14(2), 329-373 (1990), http://dx.doi.org/10.1016/0165-1889(90)90025-c. 
6. Tesfatsion, L.: Agent-based computational economics: modeling economies as complex adaptive systems. Information Sciences 149(4), 262-268 (2003), http://dx.doi.org/10.1016/s0020-0255(02)00280-3.

7. Tucnik, P., Blecha, P., Kovarnik, J.: Adaptation to Market Development Through Price Setting Strategies in Agent-Based Artificial Economic Model. Computational Collective Intelligence, 548-557 (2017), http://dx.doi.org/10.1007/978-3-319-67074-4_53.

8. Tucnik P., Nemcova Z.: Production Unit Supply Management Solution in Agent-Based Computational Economics Model. In: Barbucha D., Nguyen N., Batubara J. (eds) NEW TRENDS IN INTELLIGENT INFORMATION AND DATABASE SYSTEMS. STUDIES IN COMPUTATIONAL INTELLIGENCE, vol 598, pp. 343-352 Springer, Cham (2015). 